\title{
Zoning Supporting Design of Deep Foundation Pit Based on Controlling Deformation of Surrounding Buildings
}

\author{
Ding Jihui ${ }^{1}$, Shen $\mathrm{Yu}^{2}$, Li Taotao ${ }^{1}$, Wang Yan $^{3}$, Zhao Tuo ${ }^{4}$, Wang Weiyu ${ }^{4}$ \\ ${ }^{1}$ Department of Civil Engineering, College of Civil Engineering and Architecture, Hebei University, Baoding, China \\ ${ }^{2}$ Supervision Office, Shanghai Electronics Industry School, Minhang District, Shanghai, China \\ ${ }^{3}$ Emergency Command and Dispatch Center, Tanshan Communication Bureau, Tangshan, China \\ ${ }^{4}$ Foundation Research Institute, Hebei Academy of Building Research, Shijiazhuang, China
}

Email address:

dingjihui@126.com(Ding Jihui), Shenyu6@163.com(Shen Yu), 1654759751@qq.com(Li Taotao), Wangy78@163.com(Wang Yan), monkey856@126.com(Zhao Tuo),weiyu_w@163.com(Wang Weiyu)

\section{To cite this article:}

Ding Jihui, Shen Yu, Li Taotao, Wang Yan, Zhao Tuo, Wang Weiyu. Zoning Supporting Design of Deep Foundation Pit Based on Controlling Deformation of Surrounding Buildings. International Journal of Architecture, Arts and Applications. Vol. 3, No. 5, 2017 , pp. $73-78$. doi: $10.11648 /$ j.ijaaa.20170305.12

Received: September 19, 2017; Accepted: October 28, 2017; Published: November 23, 2017

\begin{abstract}
According to the deep foundation pit of a spatial dimension in Shijiazhuang, the retaining and protection structure of pile and anchor cable is selected because of property of the soil layer. The interaction between the support system and the surrounding buildings is analyzed by the finite difference method, on this basis, according to the deformation of surrounding environment and the stability requirement of slope, the deep foundation pit is made zoning supporting design. When there is a building on the outside of foundation pit wall and the building is located in the middle side of the slope wall, the effect of building on horizontal displacement of foundation pit is mainly happened in the middle of the slope wall, and the range is $(0.22 \sim 0.78) \mathrm{L}$ ( $\mathrm{L}$ is the length of the foundation pit) or $1.85 \mathrm{~A}$ ( $\mathrm{A}$ is the length of the building along the direction of the pit). The settlement and different settlement of the building foundation can be controlled by increasing the stiffness of the retaining structure, such as increasing the diameter of pile or reducing the spacing of pile. When reducing the diameter of pile or increasing the spacing between the piles in the west side of the slope, the deformation and different deformation of the area are obviously reduced, so as to meet the requirements for the deformation of the underground pipelines outside the slope wall.
\end{abstract}

Keywords: Deep Foundation Pit, Adjacent Building, Pile Anchor Cable Support System, Zoning Supporting Design

\section{Introduction}

Deep foundation pit is a spatial system with dimension in the plane and depth, and its force in stress and deformation has obvious spatial effect. Fook-Hou Lee etc. [1] had monitored and numerically simulated the deep foundation pit of a soft soil layer in Singapore. The results show that the spatial numerical analysis is more valuable than the slope deformation obtained by plane numerical analysis. The size of the length of the foundation pit, the ratio of the length of the short edge and the rigidity of the retaining structure affect the deformation of the foundation pit.

Ding Jihui, Yuan Man, Zhang Qin etc. [2-4] put forward the concept of efficiency factor of earth pressure, the spatial distribution of deformation and internal force on the cantilever retaining structure of deep foundation pitwere analyzed, and discussed the spatial effects of the two-row-pile retaining structure of deep foundation by the utilization factor of earth pressure. Ding Jihui, Fan Fei etc. [5] pointed out that spatial effect was significantly reflected in the deformation, earth pressure and other aspects though the field monitoring results. Wang Weiyu and Ding Jihui etc. [6, 7] analyzed the interaction between the supporting system of the foundation pit and the surrounding building by the finite difference method. Clough and O'Rourke [8] found that the surface settlement of hard clay and sand decreases with the distance from the retaining structure and given the deformation areas. Sighs and $\mathrm{Ou}$ [9] were divided the influence area of the surface settlement of the retaining structure outside the foundation pit into the major influence area and the minor 
settlement area, and given the range of the surface settlement outside wall of the foundation pit and the vertical displacement of the ground surface.

According to the deep foundation pit of a spatial dimension in Shijiazhuang, the retaining and protection structure of pile and anchor cable is selected. The finite difference method is used to analyze the interaction between the supporting system of foundation pit and the surrounding buildings. On this basis, the sectionalized design is carried out, and the zoning design method of deep foundation pit is put forward.

\section{The Thought of Zoning Design in Foundation Pit}

(1) Analyze the influence of excavation on surrounding environment

The unloading of deep foundation pit will inevitably change the stress field and displacement field of surrounding soil. In the end, it may cause passive deformation of adjacent Foundations which will affect the normal use of existing structures. Analyze the scope and strength of influence on foundation pit, which is from surrounding buildings or structures, increase the stiffness of the support structure or select supporting structure form with relatively large stiffness.

(2) Standard for deformation of adjacent buildings

The environmental impact caused by unloading of foundation pit excavation is inevitable, but the excavation must ensure the safety of the surrounding buildings. The controlling standard for deformation of the surrounding buildings is the key to the design of retaining structures. The additional deformation of the building caused by the excavation of the foundation pit shall be satisfied:

$$
\xi_{2} \leq \xi_{0}-\left(\xi_{1}+\xi_{3}\right)
$$

where, $\xi_{0}$ is the allowable value for foundation deformation of building; $\xi_{1}$ is the existing deformation value of a building; $\xi_{2}$ is the controlling deformation of foundation based on the excavation of foundation pit; $\xi_{3}$ is deformation value of foundation in later stage of building (Minimum value is 0 ).

The allowable and maximal deformation $\xi_{0}$ of different buildings can be chosen from the current specification [10]. The controlling deformation of excavations and adjacent underground pipeline can be chosen from the current specification [11]. Referent values for controlling deformation of foundation pit can be chosen from the current specification [12].

\section{General Situation of Engineering}

As shown in Figure 1, there is a five-story building in the form of brick-concrete structure around the east side of the foundation pit. The load on each floor is considered as $15 \mathrm{kPa}$, and the total load is $75 \mathrm{kPa}$. The buried depth of the residential building is $1.5 \mathrm{~m}$, the length $\mathrm{A}$ is $40 \mathrm{~m}$, and the width $\mathrm{B}$ is $20 \mathrm{~m}$. The excavation depth of deep foundation pit $\mathrm{H}$ is $10.0 \mathrm{~m}$, the distance between the building and the foundation wall is $\mathrm{C}$, and the distance from the south wall is $\mathrm{D}$. The distribution and main parameters of a section soil layer, the design parameters of support system are seen reference [7].

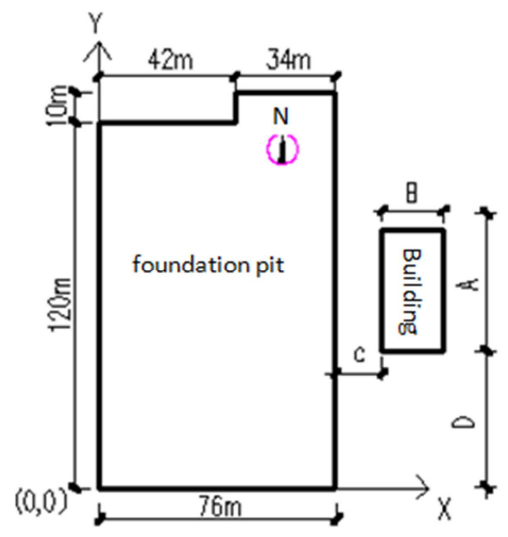

Figure 1. Floor plan of foundation pit [7].

\section{The Zoning Design Scheme of the Deep Foundation Pit}

There are three situations in the surrounding environment of deep foundation pit:

(1) There is a building near the slope of the east side, and the distance from the slope is $\mathrm{C}=0.5 \mathrm{H}$.

(2) There is an underground pipeline around the slope of the west side.

(3) The south side and the north side are the short side of the foundation pit, where no special protection against the surrounding environment is required, and the support scheme is used.

According to the current standard [9-11], combining with the depth of soil layer, ground water, foundation pit, surrounding pipelines and buildings, the alarm values of foundation pit during monitoring are determined. The controlling value of the horizontal displacement is $20.0 \mathrm{~mm}$, the top vertical displacement is $10.0 \mathrm{~mm}$, the deep horizontal displacement is $30.0 \mathrm{~mm}$, the vertical displacement of building is $15 \mathrm{~mm}$, the vertical displacement of pipeline is $10 \mathrm{~mm}$, the controlling value of different settlement of pipeline and building is $2 / 1000$.

\subsection{Deformation Analysis of Slope Wall on East Side}

When there is building on the outside of foundation pit wall and the building is located the middle side of the slope wall, the effect of building on slope horizontal displacement of foundation pit is mainly happened in the middle of the slope wall, and the range is $(0.22 \sim 0.78) \mathrm{L}$ ( $\mathrm{A}$ is the length of the foundation pit) or $1.85 \mathrm{~A}$ ( $\mathrm{A}$ is the length of the building). In order to ensure the normal use of the building around the foundation pit, it is necessary to reduce the deformation of the middle slope wall and increase the strength of the supporting structure in the middle part, that is, increasing the diameter of pile or reducing the spacing of pile in the slope whose range is 


\section{$1.85 \mathrm{~A}$ (that is $70 \mathrm{~m}$ ).}

(1) Influence of pile spacing on deformation

In the middle east slope wall part of the range of $70 \mathrm{~m}$, when the pile spacing is $2.0 \mathrm{~m}, 1.8 \mathrm{~m}, 1.6 \mathrm{~m}, 1.4 \mathrm{~m}$, the horizontal displacement of the foundation pit is obtained through the simulation (as shown in Figure 2).

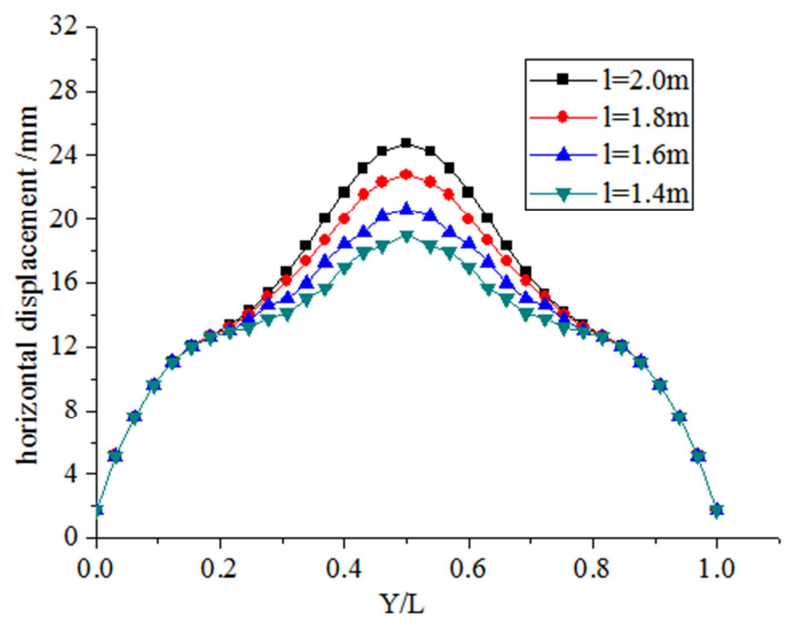

Figure 2. The horizontal displacement of the east slope with different pile spacing.

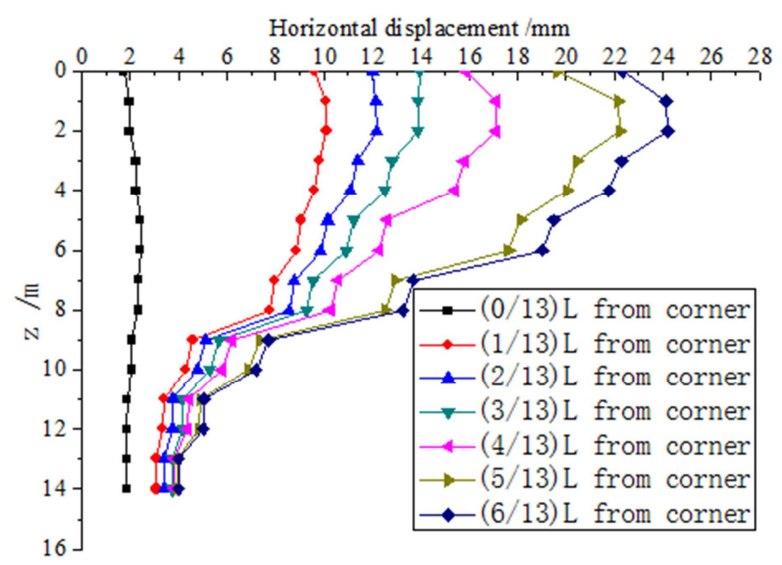

Figure 3. When $l=1.8 \mathrm{~m}$, horizontal displacement map.

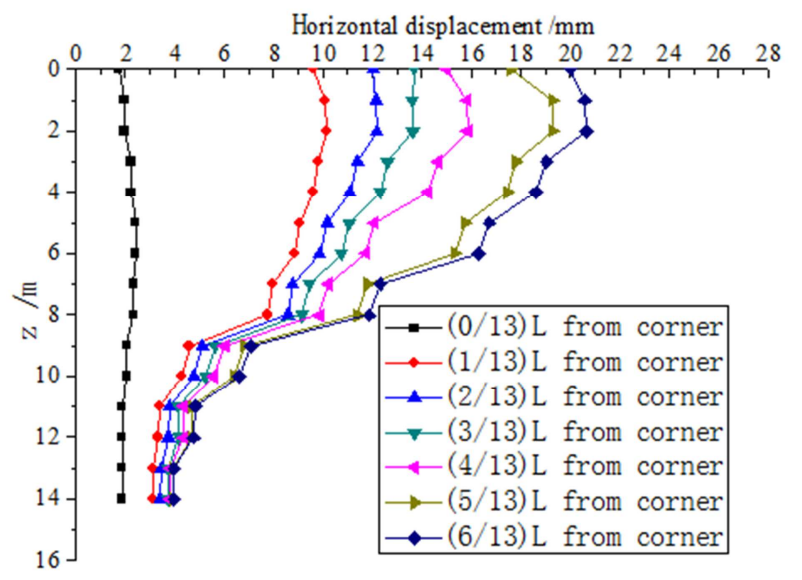

Figure 4. When $l=1.6 \mathrm{~m}$, horizontal displacement map.

From Figure 2, the horizontal displacement of foundation pit significantly is reduced with pile spacing decreased. When the spacing of the piles is reduced from $2 \mathrm{~m}$ to $1.4 \mathrm{~m}$, the maximal horizontal displacement is reduced from $24.774 \mathrm{~mm}$ to $18.986 \mathrm{~mm}$. When the pile spacing is changed to $1.4 \mathrm{~m}$, the maximal horizontal displacement of the slope wall is less than $20 \mathrm{~mm}$, and the design requirements can be meet.

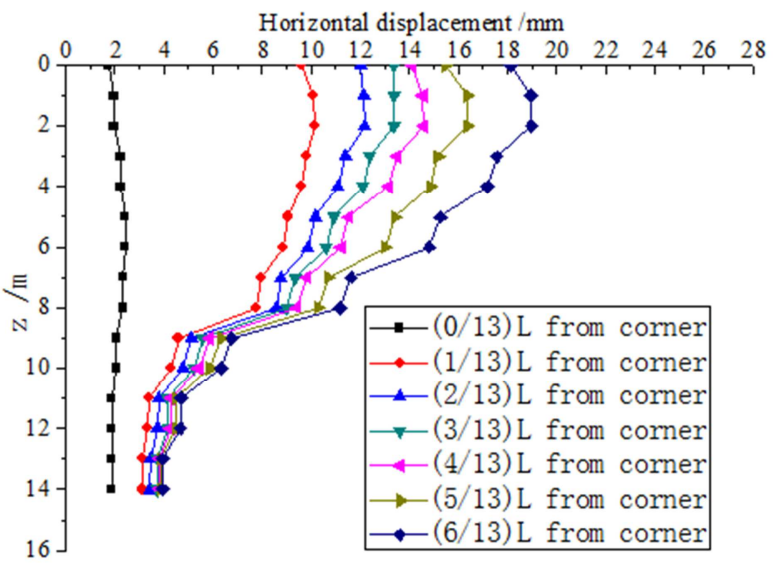

Figure 5. When $l=1.4 m$, horizontal displacement map.

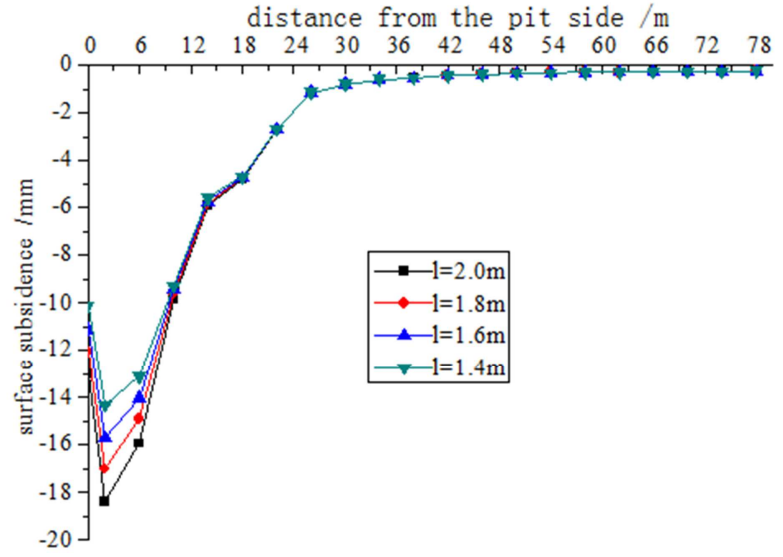

Figure 6. Comparison of surface subsidence on the east side.

Figure 3 - Figure 5 show deep horizontal displacements of the slope wall that is at the eastern side of the foundation pit., when the pile spacing is respectively $1.8 \mathrm{~m}, 1.6 \mathrm{~m}$ and $1.4 \mathrm{~m}$. The results of calculation show that the deep horizontal displacement in three cases of changing pile spacing can meet the requirement that is not greater than $30.0 \mathrm{~mm}$.

Figure 6 is the ground subsidence corresponding to different pile spacing. By reducing the spacing of pile, the surface subsidence on the east slope wall of the foundation pit is decreased gradually, but the influent range is mainly within the range of $12.0 \mathrm{~m}$ in the slope wall. When the pile spacing is reduced to $1.4 \mathrm{~m}$, the maximal value of surface subsidence is $14.320 \mathrm{~mm}$, and less than $15 \mathrm{~mm}$, which meet the requirements of the maximal displacement of the building foundation.

(2) The influence of pile diameter on deformation

From Figure 7, the horizontal displacement of foundation pit significantly is reduced with pile diameter increased. When the pile diameter is increased from $1.0 \mathrm{~m}$ to $1.6 \mathrm{~m}$, the maximal horizontal displacement is reduced from $24.774 \mathrm{~mm}$ to 
$18.884 \mathrm{~mm}$. When the diameter of pile is changed to $1.6 \mathrm{~m}$, the maximal horizontal displacement of the slope wall is less than $20 \mathrm{~mm}$, which can be meet the design requirements.

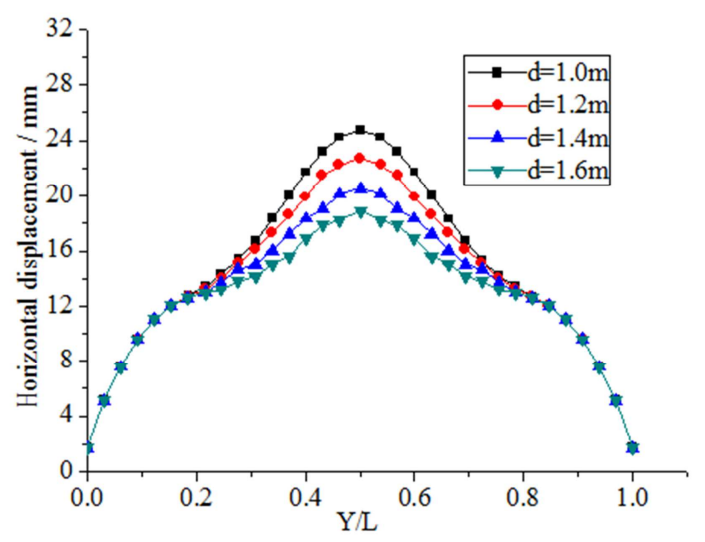

Figure 7. The horizontal displacement of the east slope wall with different pile diameter.

Figures 8-10 show deep horizontal displacements of the east slope wall at different positions, when the pile diameter is respectively $1.2 \mathrm{~m}, 1.4 \mathrm{~m}$ and $1.6 \mathrm{~m}$. The results of calculation show that the result in three cases of changing pile diameter can meet the requirements of deep horizontal displacements that is not greater than $30.0 \mathrm{~mm}$.

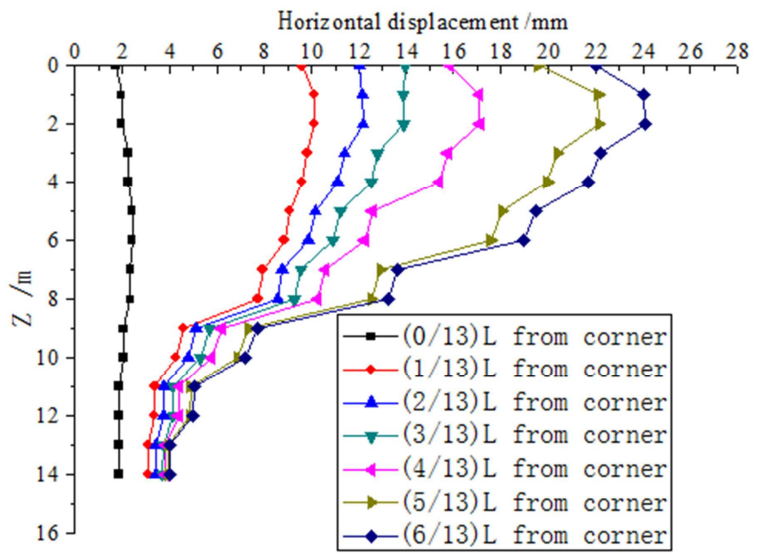

Figure 8. When $d=1.2 \mathrm{~m}$, horizontal displacement map.

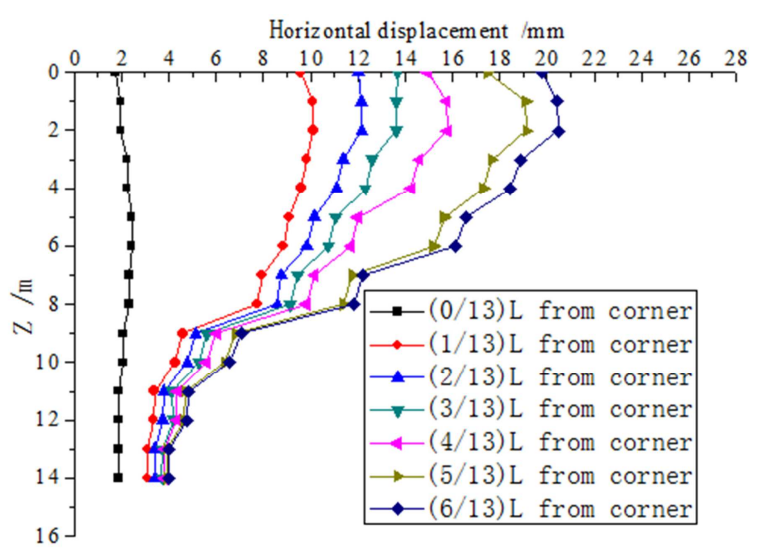

Figure 9. When $d=1.4 m$, horizontal displacement map.

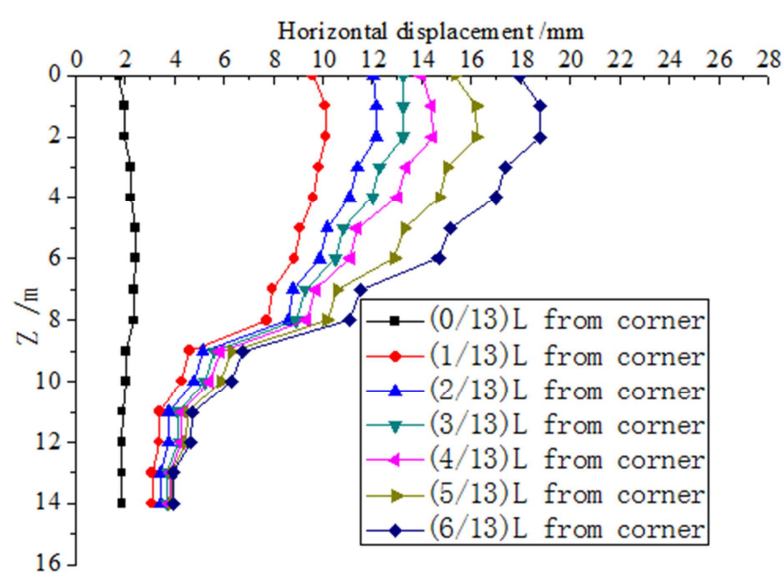

Figure 10. When $d=1.6 m$, horizontal displacement map.

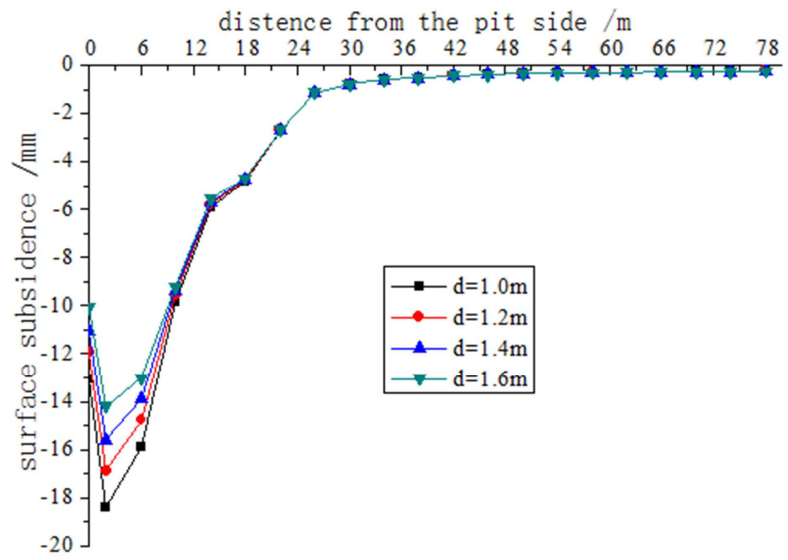

Figure 11. Comparison of surface subsidence on the east side.

Figure 11 is the ground subsidence corresponding to different pile diameter. By increasing the diameter of pile, the surface subsidence on the east slope wall of the foundation pit is decreased gradually. When the pile diameter is increased to $1.6 \mathrm{~m}$, the maximal value of surface subsidence is decreased $14.216 \mathrm{~mm}$, and less than $15 \mathrm{~mm}$, which meet the requirements of the maximal displacement of the building foundation.

\subsection{Deformation Analysis of Slope Wall on West Side}

There are underground pipelines on the west side of the foundation pit, and the deformation and displacement of the underground pipelines need to be controlled when the soil body is excavated. The difference between the horizontal displacement and the settlement of the middle slope wall is reduced as much as possible, so as to reduce the influence of the excavation on the underground pipeline around the slope wall.

(1) Influence of pile spacing on deformation

With the distance from negative angle of foundation pit increased, top level displacement increases gradually, and the maximal value is $13.368 \mathrm{~mm}$. In the middle of the slope wall, the maximal horizontal displacement of the deep wall and the maximal value of the surface subsidence are $13.458 \mathrm{~mm}$ and $7.889 \mathrm{~mm}$. Due to the deformation of the slope within $12 \mathrm{~m}$ of 
the foundation pit, the deformation of slope wall is small, and the spacing of pile is increased to $2.1 \mathrm{~m}$ so as to reduce the settlement difference.

Figure 12 is the horizontal displacement of the west slope wall near the foundation pit, and Figure 13 is the surface subsidence of the west slope wall near the foundation pit. From Figure12 and Figure 13, the displacement and settlement difference at the middle of the foundation pit is reduced.

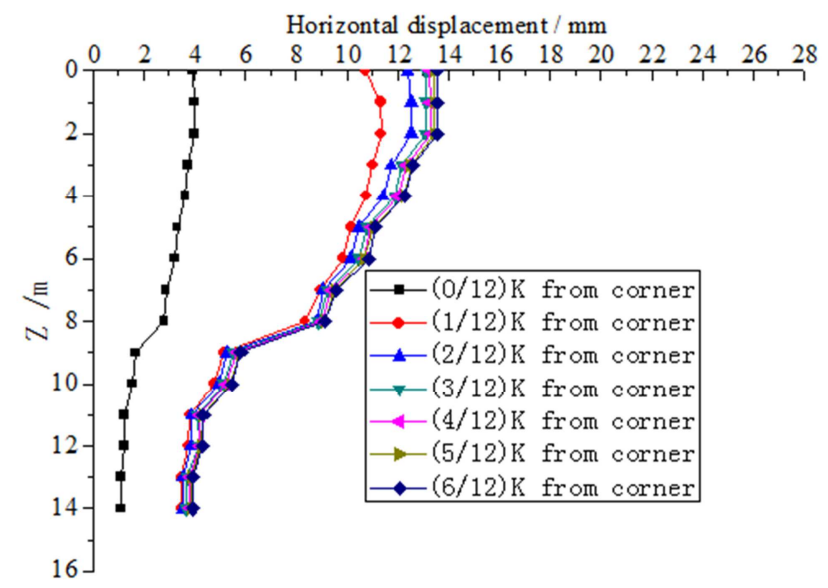

Figure 12. When $l=2.1 \mathrm{~m}$, horizontal displacement map in the west side.

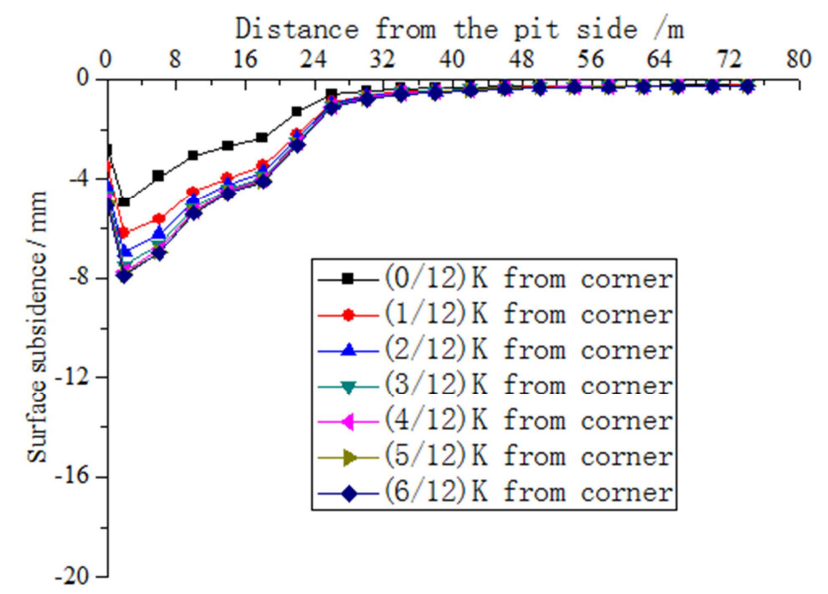

Figure 13. When $l=2.1 \mathrm{~m}$, the surface subsidence on the west side.

(2) The influence of pile diameter on deformation

Figure 14 and Figure 15 is the map of deep horizontal displacement and subsidence, when pile diameter within the range that is $12 \mathrm{~m}$ away from the corner of the west slope is reduced to $0.9 \mathrm{~m}$. The calculation results of increasing spacing are similar to those of reducing the pile diameter. When the diameter of the pile is reduced to $0.9 \mathrm{~m}$, or the center distance of the pile is increased to $2.1 \mathrm{~m}$ in west corner of the foundation pit that is $0.1 \mathrm{~K}$ ( $\mathrm{K}$ is the length of the slope wall), it can reduce displacement and different settlement so as to ensure the use of the surrounding underground pipeline effectively.

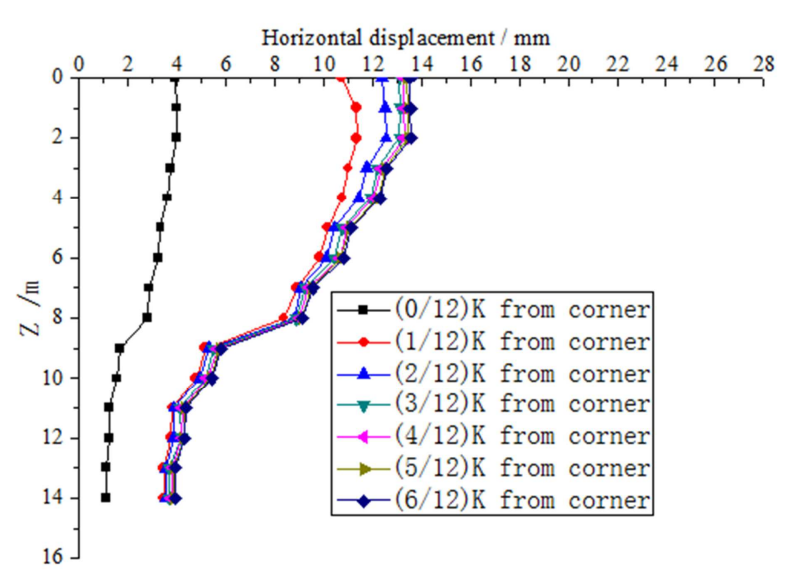

Figure 14. When $d=0.9 \mathrm{~m}$, horizontal displacement map in the west side.

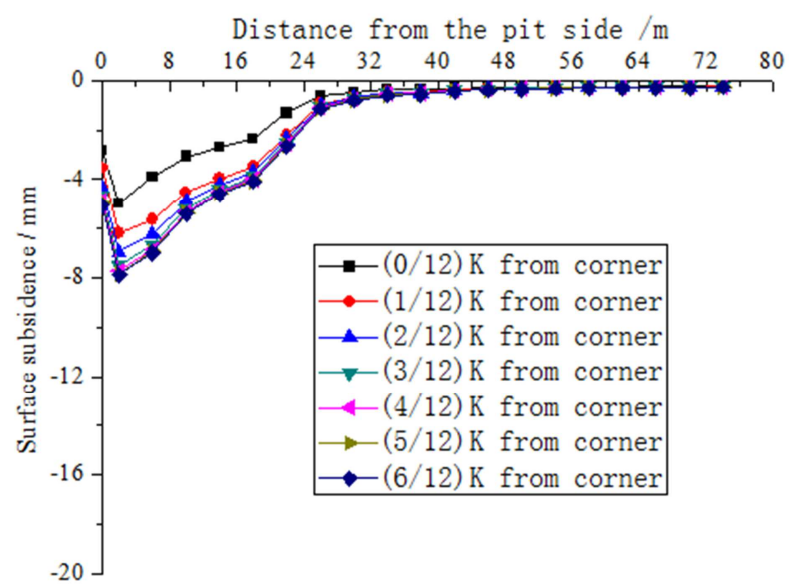

Figure 15. When $d=0.9 m$, the surface subsidence on the west side.

\section{Conclusion}

According to the different deformation requirements of deep foundation pit, a new method of partition design in deep foundation pit is put forward, to ensure that the deformation of surrounding soil will not affect the normaluse and safety of the surrounding buildings and foundation pit construction.

(1) When there is building on the outside of foundation pit wall and the building is located the middle side of the slope wall, the effect of building on horizontal displacement of foundation pit is mainly happened in the middle of the slope wall, and the range is $(0.22 \sim 0.78) \mathrm{L}$ or $1.85 \mathrm{~A}$ ( $\mathrm{A}$ is the length of the building). When the pile spacing in the range that is $1.85 \mathrm{~A}$ in the eastern slope wall is reduced to $1.4 \mathrm{~m}$, or the pile diameter is increased to $1.6 \mathrm{~m}$, the horizontal displacement, deep horizontal displacement, surface settlement and the maximal settlement, different settlement of the building can be controlled.

(2) The $0.1 \mathrm{~K}(\mathrm{~K}$ is the length of the slope wall) on the west side of the foundation pit has obvious spatial effect. In order to protect the normal use of the underground pipelines on the west side of the slope wall and reduce the differential deformation, the pile spacing within the $0.1 \mathrm{~K}$ away from the corner is increased from $0.9 \mathrm{~m}$ to $2.1 \mathrm{~m}$, or the pile diameter is decreased from 1.0 to 0.9 . 


\section{References}

[1] Lee, F. H. Yong. K. Y. QUAN, K. C. N. and CHEE, K. T. Effect of corners in strutted excavations: field monitoring and case histories [J]. Journal of Geotechnical and Geoenvironment Engineering, 1998, 124(4):339-348.

[2] Ding Jihui, Yuan Man \& Zhang Qin. The analysis of spatial effects of the soil pressure on cantilever retaining structure based on elastic resistance method [J]. Engineering Mechanics, 2012:29(S1): 136 -140.

[3] Ding Jihui, Zhang Qin, Han Lijun et al. Calculation method of soil pressure utilization factor on cantilever supporting structure of deep excavation [C]. International Conference on Electric Technology and Civil, Wuhan, China, 2011: 4830-4837.

[4] Yuan Man, Ding Jihui \& Zhang Qin. Analysis of Spatial Effects of Earth Pressure on Two-row Pile Structure of Foundation Pit Based on Elastic Resistance Method [J]. Open Journal of Civil Engineering, 2011.

[5] Ding Jihui, Fan Fei, etc. Monitoring and Analysis of Deformation Laws of Deep Foundation Pit Considering Spatial Effect [J]. International Journal of Engineering Research \& Science,2016:2(9):64-71.

[6] Wang Weiyu \& Zhao Tuo. Numerical analysis of space effect of foundation pit excavation under unsupported condition [C]. Proceedings of the 25th National Conference on Structural Engineering, 2016, (2):56-59.

[7] Jihui-Ding, Taotao-Li, Xiaohui-Wang etc.. Analysis of Interaction between Adjacent Buildings and Deformation of Foundation Pit [J]. International Journal of Engineering and Technical Research, 2017,7(7):102-109.

[8] Clough G W, O'Rourke T D. Construction induced movements of in situ walls [C]//Design and performance of earth retaining structures. ASCE, 1990: 439-470.

[9] Ou C Y, Hsieh P G, Chiou D C. Characteristics of ground surface settlement during excavation [J]. Canadian Geotechnical Journal, 1993, 30(5):758-767.

[10] GB 50007-2011, Code for design of building foundation [S]. Beijing: China Architecture\& Building Press, 2012.

[11] GB50497-2009, Building foundation pit monitoring technical specifications [S]. China Architecture\& Building Press, 2011.

[12] GB50202-2002, Code for acceptance of construction quality of building foundation [S]. China Architecture\& Building Press, 2002. 